\title{
La escisión del héroe a partir de los procesos de escritura en Siglo de $o(g) r o$, de Manlio Argueta y La lluvia amarilla, de Julio Llamazares
}

\author{
Ericka Calderón Rojasi, Universidad Nacional
}

Recibido: 6-08-2014

Aprobado: 4-11-2014

\section{Resumen}

En este artículo se estudia la escisión heroica en la literatura de posguerra en las novelas Siglo de o(g)ro (1997), del salvadoreño Manlio Argueta, y La lluvia amarilla (1988), del español Julio Llamazares. Dados los contextos de guerra y posguerra, marcados por el miedo, la soledad, la cercanía con la muerte y la sobrevivencia, los personajes protagonistas se modifican internamente: se dividen en quienes quieren ser y quienes deben ser para sobrevivir. Estos cambios se demuestran en las estrategias de escritura, pues nos encontramos frente a novelas donde se rompen estructuras de narración, como la perspectiva, la focalización y la linealidad del tiempo; por ende, los procesos internos vividos por los personajes se manifiestan a través de los componentes narrativos.

\section{Abstract}

\section{The Split of the Hero Based Upon the Writing Processes in Siglo de $o(g) r o$, by Manlio Argueta and La Iluvia amarilla, by Julio Llamazares}

This article examines the heroic split in the postwar literature in the novels Siglo de o(g)ro (1997), by the Salvadoran author Manlio Argueta, and La lluvia amarilla (1988), of the Spanish writer Julio Llamazares. Given the contexts of both war and postwar, marked by fear, loneliness and the closeness to death and survival, the protagonists modify themselves internally: They split into who they wish to be and who they should be in order to survive. These changes are shown through their writing strategies since we are in the presence of novels where narrative structures are broken, like in the case of perspective, focalization, time linearity. Thus, the internal processes lived by the characters are shown through the narrative components.

\section{INTRODUCCIÓN}

El concepto del héroe en la literatura ha variado a lo largo del tiempo, desde la imagen mítica del personaje triunfador de la época clásica, cuyas bases teóricas se encuentran en las propuestas de Joseph Campbell, hasta el héroe cotidiano, el cual se encuentra fundamentado en los planteamientos bajtinianos, cercano a la realidad contemporánea, cargado de cuestionamientos y cuyo rasgo
Ericka Calderón Rojas. La escisión del héroe a partir de los procesos de escritura en Siglo de o(g)ro, de Manlio Argueta y La Iluvia amarilla, de Julio Llamazares. Revista Comunicación. Año 35, vol. 23, núm. 2, juliodiciembre, 2014. Tecnológico de Costa Rica. ISSN impreso: 0379-3974/ e-ISNN: 1659-3820

i Master en Literatura, graduada de la Universidad de Costa Rica. Docente de la Universidad Nacional de Costa Rica.

PALABRAS CLAVE:

escisión/fragmentación heroica a partir de componentes literarios, narrativa de posguerra.

\section{KEY WORDS:}

Heroic split or fragmentation departing from literary components, postwar narrative. 


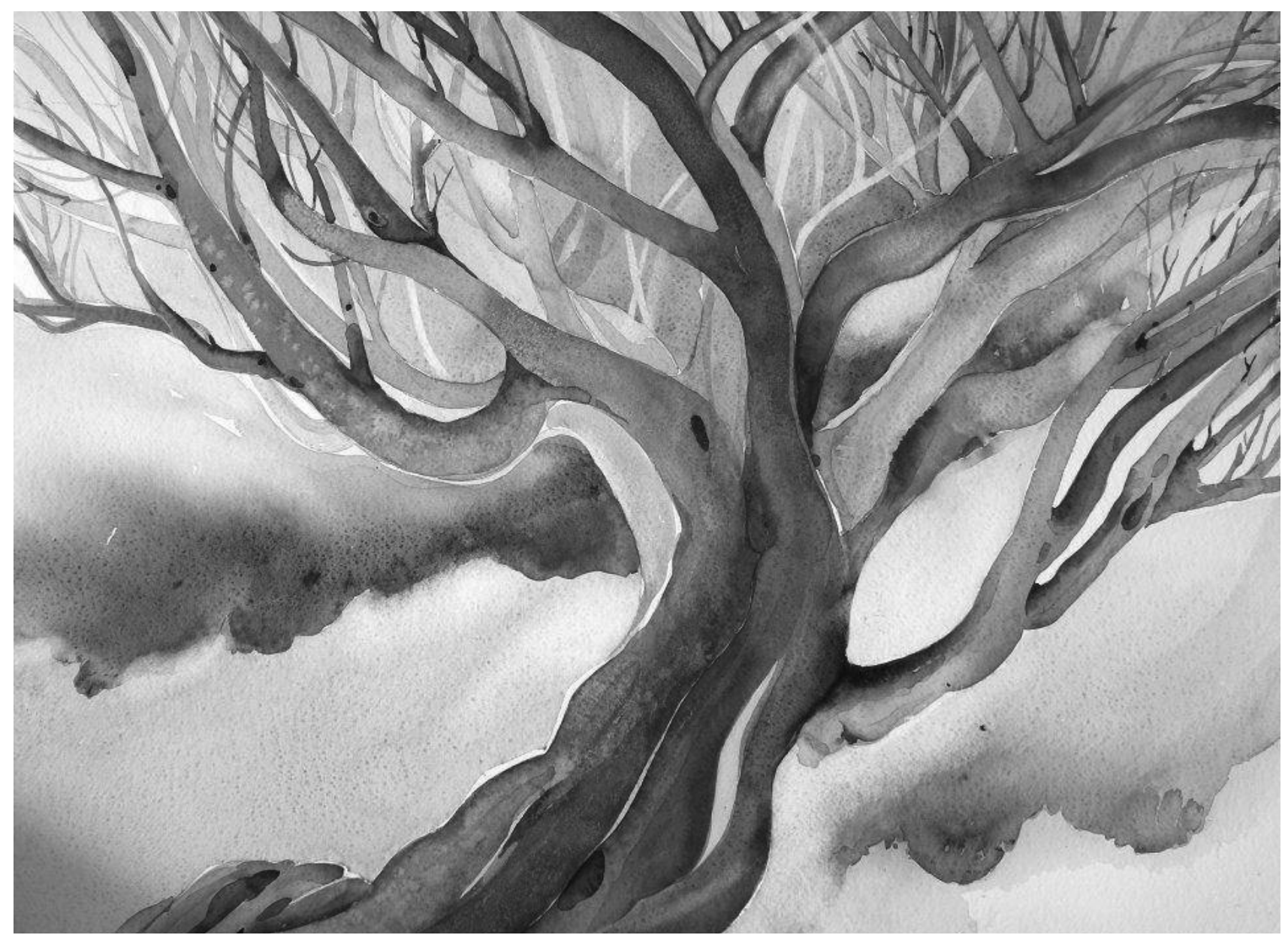

Dunia Molina M.

primordial ya no será el triunfo sino la sobrevivencia -el de la novela-.

Dentro de esas modificaciones en el término del héroe se incluye la problematización del yo, ligada con el avance espacio - temporal vivido por una sociedad y sus características, tales como el aumento en la tecnología, el cambio en las tradiciones y creencias, la caída de los grandes hitos del inconsciente colectivo y las problemáticas sociales, políticas y económicas de un periodo histórico particular. Al respecto, Manuel Alberca menciona: muchas novelas [...] establecen una dialéctica y tensa ecuación entre lo ficticio y lo vivido, entre lo real y su simulacro a partir de las diversas formas de las novelas del yo, al alumbrar el binomio vida-literatura (Alberca, 2007, p. 60).

Por otra parte, los procesos armados, sean internos o externos, se constituyen como un propulsor del cambio generado en el personaje principal de la novela, hasta el punto de atravesarlo, marcarlo y convertirlo en un ser escindido o desdoblado.
Esta escisión se marca por las imposiciones, falta de libertad o violación de los derechos humanos e individuales predominantes en el proceso de alguna guerra, los cuales obligan a los individuos a vivir bajo el miedo, la aprehensión, el silencio y la distancia con respecto a sus creencias y a los otros. Dadas estas condiciones, se produce una enajenación del ser humano, quien debe dejar de ser sí mismo para soportar los avatares del conflicto armado y así asegurarse la supervivencia en un contexto de muerte y frialdad.

Como consecuencia de esta situación, en los personajes literarios se evidencia, por un lado, el miedo, la frustración y el silencio y, por el contrario, una estrategia de distanciamiento consciente del tema de la guerra; ambos casos hacen notar la escisión padecida por los personajes en el contexto real, lo cual se traspasa hasta los literarios.

Es por eso que resulta importante resaltar cómo la literatura de posguerra se convierte en un medio de problematización de las situaciones vividas y en un 
método de recuperación de la memoria colectiva, un recurso para luchar contra el olvido de la memoria histórica.

De ahí nace la propuesta temática para este artículo, cuyo objetivo es evidenciar la escisión heroica llevada a cabo en los contextos de posguerra por medio de la lectura comparada de Siglo de o(g)ro, de Manlio Argueta (1997) y La lluvia amarilla, de Julio Llamazares (1988).

Si bien dichas obras fueron escritas en épocas diferentes y hacen referencia a dos lugares geográficos distintos, pueden enmarcarse en una temática similar: las consecuencias de los procesos armados internos, tanto para la sociedad, discriminada y perdedora, como para el personaje protagónico, quien, dados los cambios sociales provocados por la guerra, se escinde (o se modifica) internamente.

Asimismo, ambos textos comparten el tema de la recuperación de la memoria colectiva mediante la puesta en escena de los recuerdos individuales de ambos personajes principales, Alfonso Trece Duque, de Siglo de o(g)ro y Andrés de Casa Sosa, de La lluvia amarilla.

Con respecto a la pertinencia de la comparación entre dos producciones artísticas pertenecientes a diferentes épocas y regiones, es válida la propuesta de Foucault (1990), quien asegura que distintos hechos históricos pueden ligarse mediante una línea simbólica común, es decir, la existencia de relaciones o similitudes ideológicas, las cuales crean un principio de unidad y explicación (p.75).

Asimismo, al tratarse de una lectura comparada se hace permisible la distancia temporal y geográfica entre las dos obras, pues según los teóricos de la comparatística, cuyas bases provienen de la polifonía bajtiniana, es posible la repetición de hechos en épocas, lugares y problemáticas distintos.

Una vez aclarado esto, puede continuarse con el análisis. En primer lugar, se requiere definir el concepto de novela de posguerra, el cual se entiende desde las investigaciones de Erick Aguirre (2004), Alexandra Ortiz Wallner (2006) y Ramón Luis Acevedo (1992), entre otros, según la cual puede considerarse como literatura de posguerra toda aquella producida después de los conflictos y hasta la actualidad, cuya temática sea las consecuencias directas e indirectas causadas por dicho conflicto. Así, afirma Aguirre (2004), la literatura de posguerra es una literatura del desencanto $y$, a la vez, una posibilidad de buscar y explorar nuevas formas de representación de la intimidad y de la construcción de la subjetividad. A lo cual agrega Ortiz Wallner (2006) la manifestación de la violencia y su representación narrativa, así como la disolución de los valores patrióticos de antaño como un aspecto fundamental.

Se trata entonces de analizar y entender las diferentes expresiones literarias en los países del istmo desde una perspectiva regional y su ubicación en el proceso de desarrollo de las literaturas hispanoamericanas, e incluso en un contexto más amplio. De este modo, es posible justificar que ambos textos pertenecen a la literatura de posguerra de sus respectivos países, dada su temática de las consecuencias psicológicas, morales y sociales vividas después de los conflictos armados internos.

\section{VISIÓN MÁS HUMANIZADA Y CERCANA AL CONTEXTO HISTÓRICO, POLÍTICO Y SOCIAL}

Darío Villanueva en Estructura y tiempo reducido en la novela (1994) plantea que la novela contemporánea ha sufrido cambios abruptos con respecto a la tradicional, basados principalmente en las nuevas perspectivas de narración. Ha surgido una reciente terminología para designar a las nuevas producciones alejadas de las estructuras convencionales del siglo pasado: la antinovela (Villanueva, 1994, p.13).

Una de las características principales es la creación de la obra partir de una serie de focos de observación secundarios sometidos a una visión central que surge gracias a sus informaciones. El nuevo narrador se esforzará por abandonar su solemne actitud épica en la que se ubica por encima del público; intentará interpelar más al lector para sugerirle una interpretación de los pasajes conflictivos, cuando no la lectura de toda la obra que tiene en sus manos, de este modo, el narrador deja de ser el Asmodeo que levanta los techos de las casas y traspasa los velos de las mentes, al mismo tiempo que va prefiriendo cada vez más mostrar que contar (Villanueva, 1994, p.25)'.

En Siglo de o(g)ro y La lluvia amarilla se puede claramente verificar esa presencia de una visión más humanizada, pues se trata de la narración de la vida de Alfonso Trece Duque y Andrés de Casa Sosa, personajes protagónicos de las novelas en estudio, respectivamente, desde una visión de la cotidianeidad, la cual ha sido fragmentada por el contexto de posguerra en el cual se desarrollan.

Si bien Neumann, citado por Rodríguez (2004), ubica este tipo de relatos del bios como una manifestación de 
la individualidad, ambas obras la traspasan gracias a la narración de la soledad, el dolor, la carencia económica y la difícil situación padecida: las circunstancias sociales difíciles sumadas a los conflictos existenciales de los héroes.

Adrede se traspasa la individualidad al narrar el ambiente vivido por todo un pueblo, una sociedad: Alfonso y su familia viven sumados en un estado crítico de pobreza, la cual se repite en grandes sectores de la población salvadoreña, a excepción de aquellos más privilegiados. Lo mismo sucede en el caso del texto español en análisis, donde la destrucción paulatina de Ainielle afecta tanto a Andrés como al resto de los habitantes del pueblo, quienes han migrado por la difícil situación. A modo de ejemplo:

[...] cuando recién acababa de colarme al estadio para el segundo tiempo; en ese período de juego los soldados se hacían los desentendidos y todos los aficionados que no podíamos pagar la entrada y que desde los árboles veíamos el primer tiempo, nos metíamos en veloz carrera para ir a coger un lugar (Argueta, 1997, p. 59).

Y también:

Hacía ya dos meses que los de Casa Julio se habían ido [...] También aquella noche, corrí a esconderme en el molino. Lo hacía siempre que alguien se marchaba para no tener que despedirme, para que nadie viera la pena que me ahogaba cada vez que, en Ainielle, otra casa se cerraba (Llamazares, 1988, p.18).

Ambos fragmentos reflejan el entorno particular de los protagonistas de cada obra, repetidos en el colectivo. Las situaciones son completamente distintas, dada la diferencia en la perspectiva de la narración: en el caso de Siglo de $O(g)$ ro se trata de la mirada de un niño, quien recuerda las experiencias de su infancia, narradas desde la jocosidad e ironía; mientras que en La lluvia amarilla se trata de la visión nostálgica del último habitante de un pueblo en destrucción. No obstante, en ambos la idea de la historia de una colectividad reflejada a través de la individualidad del personaje está presente.

Asimismo, Milagro de la Paz -lugar donde habita Alfonso Trece y Ainielle y el pueblo en proceso de desaparición habitado por Andrés de Casa Sosa- son sinécdoques de la totalidad de los países. Es decir, ese pequeño barrio de San Miguel donde abundan la pobreza, el hacinamiento, el analfabetismo, los problemas de salud, las referencias constantes a la muerte, el miedo, la represión y el silencio ejemplifican la situación vivida en El Salvador en el contexto de posguerra, parodiada con la onomástica, pues el nombre del personaje principal remite a figuras de poder político y económico ${ }^{2}$.

De la misma forma, la destrucción lenta de Ainielle, que sucede de forma simultánea a la pérdida de la fuerza física y al voluntad de Andrés, la soledad, falta de calor, individualidad y temor, muestran la situación de toda España, devastada por los efectos de la guerra civil de 1936 y la posterior dictadura de Franco, cuya duración fue de treinta y seis años. Por ende, el entorno de La lluvia amarilla ejemplifica los sentimientos de todo un pueblo ante las secuelas devastadoras vividas en la posguerra.

\section{LA OSCILACIÓN DE LA PERSPECTIVA EN SIGLO DE O(G)RO}

En Siglo de o(g)ro Alfonso Trece Duque, protagonista principal, es quien narra, en primera instancia, los acontecimientos de su vida, desde su niñez hasta finales de la juventud e inicios de la etapa adulta. Dicha narración se desarrolla, desde la teoría narratológica de Genette, mediante la focalización interna fija (en primera persona del singular):

Hay dos imágenes fundamentales en mis primeros recuerdos de niño. He dejado que flameen sus banderolas en prolongado sueño para reavivarlos en esta ocasión (Argueta, 1997, p.9).

No obstante los ejemplos anteriores, no toda la narración se desarrolla en primera persona del singular, en algunos momentos se salta de la narración interna fija a una voz narradora en tercera persona del singular:

Hasta entonces se dio cuenta Alfonso Trece que algo serio estaba pasando, y se sintió triste pues estaba perdiendo a la familia con la que estuvo acompañado desde que tiene recuerdos (Argueta, 1997, p.123).

Se podría, entonces, interpretar la existencia de una focalización variable o alternada, en palabras de Genette, o una óptica plural, según las propuestas de ViIlanueva, pues se intercalan las voces de Alfonso Trece, quien narra en primera persona, y la de un narrador, la voz en tercera persona. Sin embargo, más adelante se presenta una confusión entre ambos: las voces se alternan de la primera persona a la tercera indistintamente, 
de ese modo se insinúa que el narrador en tercera persona y Alfonso Trece Duque son el mismo:

[Tres años y medio] edad punto de partida que Alfonso Trece ha memorizado por un fundamental acontecimiento, fue cuando se trasladó a casa propia donde, medio siglo después aún vive Crista, situada en las cercanías del barrio más conmovedor de San Miguel: Milagro de la Paz; a pocos metros de la Calle de La Amargura y del estadio municipal he revisado la fecha de ese traslado, que recuerdo muy bien. Tiene tres años y medio, demasiado mínima para pensar que se existe, pero lo suficiente para saber que la edad de la razón descansa en la primera memoria (Arguet, 1997, p.10) ${ }^{3}$.

También, en la primera parte del fragmento encontramos dos verbos que hacen referencia a la tercera persona del singular. Una voz narra con distancia los hechos acaecidos a Alfonso Trece. En la segunda, los dos primeros verbos se encuentran conjugados en primera persona del singular. No obstante, es posible evidenciar que no existe un cambio en el contexto de la narración, lo cual quiere decir que tanto el narrador como Alfonso Trece Duque son la misma persona, pero hay un cambio de perspectiva dentro del discurso: una oscilación de "yo" a "él".

Más adelante este mismo juego o salto de una persona a otra se hace más evidente:

Hasta entonces se dio cuenta Alfonso Trece que algo serio estaba pasando, y se sintió triste pues estaba perdiendo a la familia con la que estuvo acompañado desde que tiene recuerdos. Había una cama de pitas donde dormían los cinco: Crista, las dos hermanas menores y el futuro poeta. La cama se hundió en el piso enfangado, por su origen de pocilga. "Ya lo vamos a poner bonito", dijo a los ojos de estupor de Alfonso, ante la noche que se acercaba, en un cuarto totalmente negro, sucio y sin luz.

Después me di cuenta que a orilla de la calle, había una habitación grande que daba a la sexta poniente y que permanecía cerrado todo el tiempo. Crista me dijo que no me acercara pues nosotros no tendríamos libre acceso al gran patio, sólo el cuarto-pocilga y a un pequeño traspatio de unos seis metros cuadrados donde la madre improvisó con tres piedras grandes una cocina de leña. [...] (Argueta, 1997, p.123) ${ }^{4}$.

En el juego u oscilación de la primera persona del singular a la tercera dentro del texto, cuyo contexto de narración es el mismo, se encuentra una muestra de la escisión del personaje, pues se da una fragmentación tanto de la figura heroica o central como de sus pensamientos y recuerdos.

Por ende, a partir de los fragmentos anteriores es posible demostrar que la voz narradora desde la tercera persona y la de Alfonso Trece son la misma. Pero también es importante resaltar la repetición que ocurre a lo largo del texto de ejemplos con la misma estructura de narración.

Sin embargo, existe un elemento externo a la diégesis, situado en el nivel psicológico, que impide unificar por completo a ambos narradores: son el mismo, pero, a la vez, existe un factor coartante de la fusión entre ambas voces.

Ese elemento delimitante es otro el contexto de posguerra. Durante los períodos de conflicto armado interno se padecen distintos traumas que producen la partición del héroe en quien desea ser y quien debe ser para poder sobrevivir y afrontar el trance bélico. Recuérdese

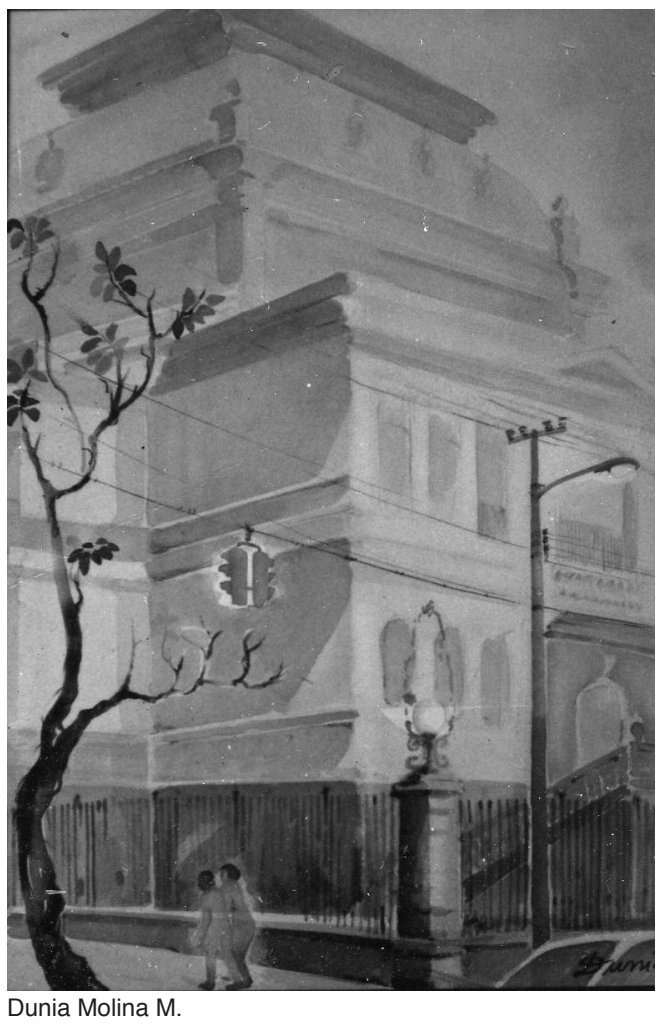


el hecho mismo del exilio sufrido en la edad adulta por Alfonso Trece: "Te prefiero en el exilio antes que muerto", son las palabras de Crista en su reencuentro (Argueta, 1997, p. 37).

\section{LA CONCEPCIÓN ESPECIAL DEL TIEMPO EN LA LLUVIA AMARILLA}

En La lluvia amarilla se evidencia una forma especial del tiempo caracterizada por saltos abruptos en la cronología y un olvido casi total de la concepción temporal. Véanse tres ejemplos para defender este argumento. He aquí el primero:

Hoy tampoco ya recuerdo el tiempo que he pasado sin dormir. Días, meses, años quizá. Hay un momento de mi vida en el que los recuerdos y los días se confunden, un punto indefinido y misterioso en el que la memoria se deshace igual que el hielo y el tiempo se convierte en un paisaje inmóvil e imposible de aprehender (Llamazares, 1988, p.122).

Igualmente:

Si mi memoria no mentía. 1961, si mi memoria no mentía. ¿Y qué es, acaso, la memoria sino una gran mentira? ¿Cómo podría yo ahora estar seguro de que aquella era, en efecto, la última noche de 1961? [...] ¿No lo habré quizá soñado o imaginado todo para llenar con sueños y recuerdos inventados un tiempo abandonado y ya vacío? ¿No habré estado, en realidad, durante todo este tiempo, mintiéndome a mí mismo? (Llamazares, 1988, p.39).

Y por último:

Una de aquellas veces, ya no recuerdo cuándo -la memoria me falla y se deshace como escarcha al evocar estos últimos años de mi vida- [...] (Llamazares, 1988, p.108).

El tiempo es un ente que se escapa a la capacidad de memoria y reconstrucción del pasado de Andrés. Pese a todos sus esfuerzos por mantener la vida en Ainielle hay tres elementos que poco a poco le ganan la batalla contra la pérdida de la memoria personal e histórica: la soledad, su edad en avance y la lluvia amarilla.

La última es una metáfora del olvido sufrido por los seres humanos a causa del tiempo, como las páginas de un libro o las fotografías adquieren un color amarillento y se va borrando la imagen al pasar de los años, así es la memoria, la cual dado el avance del tiempo, la falta de compañía y afecto, se va agotando, se marchita y se llena de color amarillo, el mismo que invade el entorno de Ainielle:

Lentamente, las horas van pasando y la lluvia amarilla va borrando la sombra del tejado de Bescós y el círculo infinito de la luna. Es la misma de todos los otoños. La misma que sepulta las casas y las tumbas. La que envejece a los hombres. La que destruye poco a poco sus rostros y sus cartas y fotografías. La misma que una noche, junto al río, entró en mi alma para no volver ya nunca a abandonarme el resto de los días de mi vida (Llamazares, 1988, p.119).

Esta estrategia de la ucronía es uno de los rasgos fundamentales para evidenciar la escisión del héroe de posguerra en la novela española en estudio: al olvidar el tiempo no tiene Andrés otra opción más que aferrarse a los recuerdos, de los que también llega a dudar; por tanto, el personaje se divide en dos seres: el de los recuerdos, el que fue en un tiempo próspero, y el del presente de la enunciación, un ser solitario, olvidado por los otros, obsesionado en su intento de mantener vivo el pueblo a través del recuerdo y fracasado.

De este modo se demuestra cómo el tiempo es un elemento muy importante para la narración, pero deja de tener linealidad desde la perspectiva del enunciador del relato, para el héroe de la posguerra, pues lo importante es plasmar los recuerdos aunque no sean guiados por un hilo temporal.

Esta ruptura de la linealidad evidencia una escisión en el personaje protagónico, pues debido a los conflictos armados internos se sufren distintas heridas, tanto a nivel físico como psicológico, las cuales pueden provocar el olvido de los acontecimientos lineales. Asimismo, la fragmentación de los recuerdos y, por ende, de la memoria, son una muestra del mismo quebrantamiento del héroe, lo cual conlleva un desmembramiento social de la colectividad.

\section{LA ANALEPSIS}

Sin lugar a dudas, la analepsis es la estrategia recurrente en ambos textos, relacionada con la escisión heroica y el intento de recuperar la memoria histórica a través de la memoria individual.

Alfonso Trece Duque desde su edad adulta narra la rememoración del pasado, el "siglo de oro" que debió 
Revista Comunicación. Volumen 23, año 35, núm. 2, julio-diciembre, 2014 (pp. 15-23)

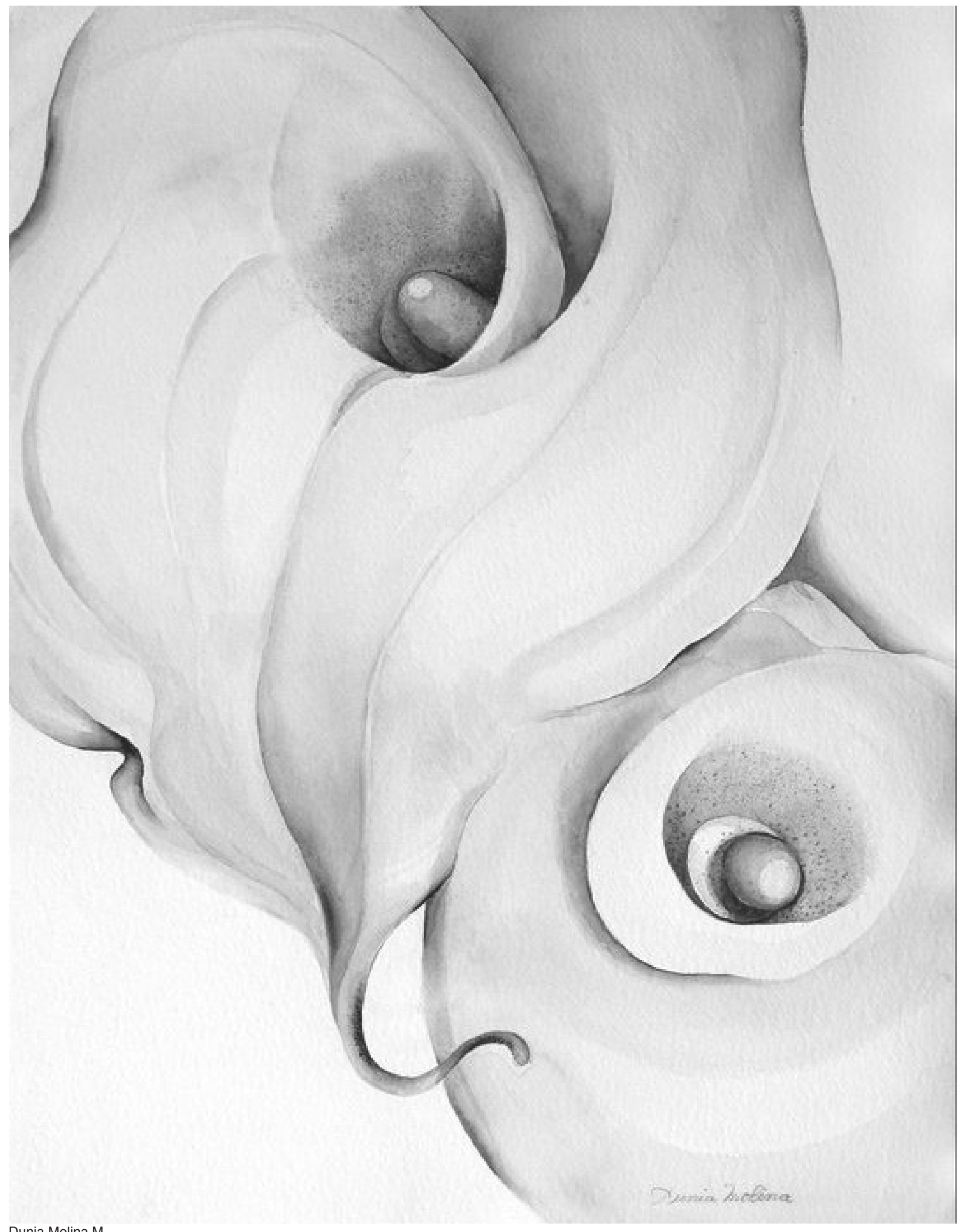


significar su niñez ${ }^{5}$, traslapado al "siglo de o(g)ro" que fue, dado el panorama de pobreza, represión y silencio como una consecuencia de los procesos armados internos de El Salvador. Por ende, toda la narración se constituye como una gran analepsis a partir de los recuerdos propios e históricos mediatizados por la mirada del niño, en los cuales la ficción tiene un papel trascendental:

Se me ocurrió entonces llevar a Ena al patio, a jugar debajo del naranjo; así puedo aprovechar para buscar hormigas leones. [...] Por pensar tantas cosas no reparo cuando Ena ha comenzado a recibir el sol vertical, tan filoso como un cuchillo al rojo fuego, mientras yo estoy tirado boca abajo en el polvo. No me doy cuenta cuando las hormigas rojas comienzan a invadir a mi hermana y la arrastran hacia su madriguera (Argueta, 1997, p.88).

Sin embargo, en la construcción de la analepsis mencionada no se utilizan verbos que ayuden a identificar el cambio temporal, la inserción de los recuerdos en el discurso, sino se narran como si constituyeran un presente desde la enunciación, como si el suceso y la narración fueran simultáneos.

Por su parte, en La lluvia amarilla, Andrés dentro de su discurso tiene constantes movimientos al pasado, ya sea lejano, como los de su niñez y las historias de sus hijos, o cercano, el recuento del cambio sufrido en Ainielle y en él mismo desde la migración de los habitantes y la muerte de Sabina:

Cuando Andrés se marchó, su madre le lloró como si hubiera muerto. Le lloró como a Sara. Le lloró y le esperó, hasta su propia muerte, lo mismo que a Camilo. Yo, en cambio, el día en que se fue, ni siquiera me levanté de la cama a despedirle.

Fue un día de febrero, en el cuarenta y nueve [...] (Llamazares, 1988, p.52).

En el caso particular de este texto de Llamazares, caso contrario al de Argueta, las analepsis se marcan con verbos que hacen posible su identificación:

Pero recuerdo el espacio violado que un día ocupó. Pero recuerdo todavía su antigua reciedumbre, la soledad de sus paredes al borde del camino de Escartín (Llamazares, 1988, p.62).
Los textos anteriores evidencian, de una forma más clara, la evocación del pasado como un intento para reconstruir el presente del pueblo, y del ser en olvido que constituyen el centro de la diégesis de La lluvia amarilla.

\section{CONSIDERACIONES FINALES}

El análisis de las nuevas formas de narrar, propuesta por Darío Villanueva, junto con la perspectiva de la focalización y el tiempo de Gerard Genette (1989), evidencian la escisión heroica en ambos textos en estudio. Desde la focalización, punto fundamental en el caso de Siglo de o(g)ro se muestra la división del narrador al identificarse en algunos casos con cercanía a la situación vivida por Alfonso Trece y, en otros, con lejanía, como si fuera un personaje diferente. Esto se debe al contexto de posguerra en el cual no todo puede ser dicho por temor a la reprensión.

A la vez, esto se logra mediante el uso de la jocosidad y la aparente inocencia con la cual Alfonso narra acontecimientos de índole social acaecidos en su vida, y por ende, en la de la colectividad.

Para finalizar, se concluye con que el tiempo se constituye como un factor de importancia dentro del análisis de la disensión del personaje protagonista, pues gracias a él se evidencia la ruptura de la memoria personal e histórica conllevada por los procesos de silenciamiento y represión sufridos por ambos personajes.

\section{NOTAS}

1 El resaltado es mío.

2 De más está explicar que se refiere a Alfonso Trece, relacionado con el rey español, y Duque con el título familiar de importancia social y financiera.

3 La falta de puntuación y de letra mayúscula al inicio del segundo párrafo son originales del texto. El resaltado es mío.

4 El resaltado es mío.

5 Recuérdese el texto de José Martí titulado La edad de oro, donde se hace referencia a la niñez como una etapa única que marca al ser humano y forma su percepción de la vida durante la edad adulta. 


\section{REFERENCIAS BIBLIOGRÁFICAS}

Acevedo, L. (1992). Rumbos de la narrativa centroamericana actual. Káñina, Revista de Artes y Letras, Universidad de Costa Rica. XVI (2), 39-51.

Alberca, M. (2007). El pacto ambiguo. De la novela autobiográfica a la autoficción. España: Biblioteca Nueva.

Aguirre, E. (2004). Novelando la posguerra en Centroamérica. Recuperado el 15 de julio del 2014 de http://istmo.denison.edu/n09/foro/novelando.html

Argueta, M. (1997). Siglo de o(g)ro. San Salvador: Concultura.

Bajtín, M. (1986). Problemas literarios y estéticos. La Habana: Editorial Arte y Literatura.

Foucault, M. (1981). Un diálogo sobre el poder y otras conversaciones Madrid: Alianza.
Foucault, M. (1990). Vigilar y castigar. Nacimiento de la prisión. México: Siglo veintiuno editores.

Foucault, M. (1999). Estrategias de poder España: Paidós.

Genette, G. (1989). Figuras III Barcelona: Lumen

Llamazares, J. (1988). La lluvia amarilla. España: Seix Barral.

Ortiz Wallner, A. (2006). Ensayar una historia cultural de Centroamérica. Istmo. Revista virtual de estudios literarios y culturales centroamericanos, núm. 12. Descargado de http:// istmo.denison.edu/n12/articulos/index.html el 2 de abril de 2014.

Rodríguez, F. (2004). Autobiografía y dialogismo. San José: Editorial de la Universidad de Costa Rica.

Villanueva, D. (1994). Estructura y tiempo reducido en la novela. Madrid: Anthropos. 